\title{
BMJ Open Readiness of health facilities to provide emergency obstetric care in Papua New Guinea: evidence from a cross- sectional survey
}

Xiaohui Hou (D) ,' M Mahmud Khan (1) ,2 Justin Pulford, ${ }^{3,4}$ Olga P M Saweri ${ }^{4}$

To cite: Hou X, Khan MM, Pulford J, et al. Readiness of health facilities to provide emergency obstetric care in Papua New Guinea: evidence from a crosssectional survey. BMJ Open 2022;12:e050150. doi:10.1136/ bmjopen-2021-050150

- Prepublication history and additional supplemental materia for this paper are available online. To view these files, please visit the journal online (http://dx.doi.org/10.1136/ bmjopen-2021-050150)

Received 13 February 2021 Accepted 26 January 2022

Check for updates

(c) Author(s) (or their employer(s)) 2022. Re-use permitted under CC BY-NC. No commercial re-use. See rights and permissions. Published by BMJ.

${ }^{1}$ Health, Nutrition and Population Global Practice, World Bank Group, Washington, District of Columbia, USA

${ }^{2}$ Health Policy and Management, University of Georgia College of Public Health, Athens, Georgia, USA

${ }^{3}$ International Public Health, Liverpool School of Tropical Medicine, Liverpool, UK

${ }^{4}$ Papua New Guinea Institute of Medical Research, Goroka, Papua New Guinea

Correspondence to Dr M Mahmud Khan Mahmud.Khan@uga.edu

\section{ABSTRACT}

Objective To measure the readiness of health facilities in Papua New Guinea (PNG) to provide obstetric care and other maternal health services.

Design Cross-sectional study involving random sample of health centres, district/rural hospitals (levels 3 and 4 facilities) and all upper-level hospitals operational at the time of survey. Structured questionnaires were used to collect data from health facilities.

Setting Health facilities in PNG. Facility administrators and other facility personnel were interviewed. Number of facility personnel interviewed was usually one for health centres and two or more for hospitals.

Participants 19 upper-level facilities (levels 5-7, provincial, regional and national hospitals) and 60 lowerlevel facilities (levels 3 and 4, health centres and district/ rural hospitals).

Outcome measures Four service-types were used to understand readiness of surveyed health facilities in the provision of maternity care including obstetric care services: (1) facility readiness to provide clinical services; (2) availability of family planning items; (3) availability of maternal and neonatal equipment and materials; and (4) ability to provide emergency obstetric care (EmOC).

Results $56 \%$ of lower-level facilities were not able to provide basic emergency obstetric care (BEmOC). Even among higher-level facilities, $16 \%$ were not able to perform one or more of the functions required to be considered a BEmOC provider. $11 \%$ of level 3 and 4 health facilities were able to provide comprehensive emergency obstetric care (CEmOC) as compared with $83 \%$ of higherlevel facilities.

Conclusion Given the high fertility rate and maternal mortality ratio (MMR) in PNG, lack of BEmOC at the first level inpatient service providers is a major concern. To improve access to EmOC, level 3 and 4 facilities should be upgraded to at least BEmOC providers. Significant reduction in MMR will require improved access to CEmOC and optimal geographic location approach can identify facilities to be upgraded.

\section{INTRODUCTION}

Effective antenatal, neonatal and emergency obstetric care (EmOC) are highly costeffective interventions vital to avert common adverse pregnancy and/or birth outcomes,
Strengths and limitations of this study

- This is the first empirical study that systematically examined the availability of maternity care in health facilities in Papua New Guinea.

- All upper-level hospitals and randomly selected fully functional health centres were surveyed.

- The readiness of facilities in the provision of obstetric care and actual provision of services were assessed using relevant indicators and signal functions.

- Service availability and readiness of facilities could not be linked with community level health outcomes.

- The sampling design selected fully functional health centres and district/rural hospitals in each of the surveyed districts implying overestimation of readiness and availability of obstetric care.

which significantly contribute to maternal mortality in poor resource settings. ${ }^{1-4}$ Basic emergency obstetric care (BEmOC) alone can avert a significant proportion of maternal deaths and up to $40 \%$ of neonatal deaths. ${ }^{5} \mathrm{~A}$ global assessment found that BEmOC facilities are consistently not available in sufficient numbers in countries with high and moderate levels of maternal mortality. ${ }^{6}$ Comprehensive emergency obstetric care (CEmOC) availability, which includes the provision of caesarean and blood transfusion services in addition to the key functions included in BEmOC, is also quite poor in many lowincome and middle-income countries. ${ }^{7}$

Maternal and child health remains a key priority area in Papua New Guinea $(\mathrm{PNG})^{8}$; however, persistently high maternal and neonatal deaths reflect numerous deficiencies. The estimates of maternal mortality ratio (MMR) in PNG vary considerably. One study by Mola and Kirby estimated the MMR for 2009 using facility-based health information system records and survey data on maternal mortality among unsupervised births from one province. The estimates imply that the 
average MMR in PNG should be approximately 500 per 100000 live births. ${ }^{9}{ }^{10}$ The neonatal mortality in PNG is also high, around 28 per 1000 live births. ${ }^{11}$ The WHO model ranks PNG 130th in the world in terms of MMR. ${ }^{12}$ The 2016-2018 PNG Demographic and Health Survey (DHS), using the sisterhood method, found that the MMR was about 205 per 100000 live births. ${ }^{13}$ Even though new DHS estimate represents a significant improvement from the previous estimate of 733 per 100000 live births in 2006, the maternal mortality in PNG remains about 24 times the MMR in neighbouring Australia. ${ }^{12}$ The DHS report also indicates that only $17 \%$ of pregnancies received a prenatal visit in the first trimester and $49 \%$ had four or more prenatal visits over the whole pregnancy. During 2012-2017, about 55\% of deliveries in PNG were supervised by trained health workers at health facilities ${ }^{13}$ indicating limited access to modern maternal healthcare services.

To reduce the MMR in any country, it is important to understand the causes of death so that appropriate interventions can be designed and adopted. In PNG, the maternal mortality registry often does not report causes of death. Reviewing the causes of deaths mentioned in the general death registry and in maternal mortality registry, one study in early 1980s found that the main causes were puerperal sepsis, postpartum haemorrhage, medical and surgical complications, prolonged or obstructed labour, ruptured uterus, deaths associated with caesarean section. ${ }^{14}$ It is likely that many of these causes of deaths have remained important even today. Clearly, deaths due to the causes indicated above cannot be avoided without timely access to health facilities that are equipped to provide a range of obstetric care services. A recent article mentioned geographically dispersed population, shortage of healthcare providers, poverty, gender inequality and low level of education as important determinants of maternal deaths. ${ }^{15}$ These aspects are, however, directly related to access to care and readiness of health facilities in the provision of maternity care.

Lifetime risk of maternal death depends on the probability of maternal death per pregnancy and the average number of pregnancies per woman over the reproductive age. The 2016-2018 PNG DHS estimated that the total fertility rate (TFR) was about 4.2 per woman, which is slightly lower than the TFR of 4.4 in 2006. Access to obstetric care and lifetime risk of maternal death can be improved by lowering the TFR as well.

Given the critical importance of timely access to appropriate obstetric care, it is essential to assess the ability and readiness of health facilities in the provision of EmOC in PNG. Due to high TFR of PNG, the demand for maternal health services will continue to increase rapidly, underscoring the urgent need for improving access to care and strengthening maternal healthcare service delivery.

Despite the high social value of maternal and newborn healthcare services in PNG, no macrolevel information is available on the ability or readiness of health facilities in the provision of the services. One recent study assessed

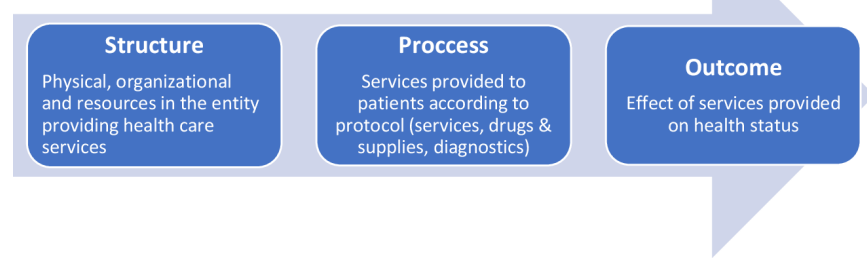

Figure 1 Three components of Donabedian approach of evaluating quality of care.

the capacity of 21 health facilities in the provision of essential surgery and anaesthesia services. ${ }^{16}$ No study on PNG, to date, has examined the readiness and ability of health facilities at the national level in the provision of obstetric care services. This study is the first attempt to understand the state of obstetric care availability in PNG.

The principal objective of this study is to measure health facility readiness to provide obstetric care and other maternal health services. Some of the measures reflect not only the readiness of the facilities in the provision of target services but also the quality of services offered. The nationally representative health facility survey allows measurement of various indicators of obstetric care services. These measures will be useful for policy makers to reform the healthcare delivery system to strengthen the provision of obstetric care and general clinical services.

\section{METHODS}

\section{Conceptual framework}

We use Donabedian's framework to analyse the readiness of obstetric care and other related services offered through the health facilities in PNG. In general, the Donabedian's approach is used to evaluate quality of care by analysing relevant structures, processes and outcomes. ${ }^{17}$ The structure measures affect processes and then processes affect outcomes, as shown in figure 1. In this study, our focus is on the evaluation of 'structure' and 'process' measures relevant for maternity care. The structure and process variables help to better understand the ability of health facilities in the provision of different service-types. Although, the impact of service provision cannot be directly measured from the facility survey data, country-level estimates of maternal mortality and morbidity imply relatively poor outcomes indicating the need for improving infrastructure and processes associated with obstetric and other maternity services.

To evaluate the ability and readiness to provide general medical care services including obstetric care, health facilities should have several infrastructural characteristics and resources. Some of the structural measures are quite general, related to the provision of any clinical service, such as general inpatient services. In addition, specific personnel, supplies and drugs must be available at the facility to be able to offer the right type of services at the right time based on the clinical needs of patients. The structural characteristics, although not directly 
related to maternity care, are the necessary aspects defining the 'readiness' of the facility in the provision of effective healthcare services. Readiness, however, does not necessarily imply actual provision of services. The infrastructural aspects act as the foundation for the provision of services, and relevant healthcare resources must be combined with the infrastructure to offer services to patients whenever needed. The process variables reflect ability to offer different types of obstetric care services and functions. The process variables for monitoring obstetric care service provision, the signal functions, are well defined and we will use the facility-level signal functions for understanding the readiness of facilities in PNG. ${ }^{18}$

\section{Study setting}

PNG is remarkably diverse with respect to geography, language and infrastructure. The country is divided into 22 provinces across four regions (Highlands, Momase and Southern, and the New Guinea Islands). Most of the country's 8 million people live in rural or peri-urban communities and are faced with significant challenges with regard to equitable access to health, education and economic opportunities.

PNG has a government-funded health system throughout much of the country. It is supplemented by government-subsidised health services provided by various Christian missions. Overall, it is estimated that churches provide $47 \%$ of primary health services, particularly in rural areas. ${ }^{19}$

Health facilities are categorised by the number and cadre of health workers employed and the services they provide and are detailed in the National Health Services Standard (NHSS) of the Government of PNG (GoPNG) ${ }^{20}$ The levels of health facilities in PNG are numbered 1 through 7 , where levels 1 and 2 provide basic primary healthcare, specifically outpatient services only. Level 3 health facilities, or health centres, provide outpatient and basic inpatient services for deliveries and minor ailments requiring observation. Level 4 health facilities, district and rural hospitals, provide general admissions, limited clinical support services including basic pharmacy and laboratory services, and depending on the employment of a medical officer, may provide surgical intervention services. Levels 5-7 health facilities provide secondary and tertiary health services as well as clinical support services, including pharmacy, laboratory and radiology. The only level 7 health facility, the Port Moresby General Hospital, is the largest and most advanced healthcare facility of PNG, employs the largest concentration of healthcare workers and provides comprehensive healthcare services.

\section{Survey design}

We conducted a health facility survey of 73 health facilities in PNG in 2015. All operational upper-level health facilities (levels 5-7) were selected for the survey. At the time of data collection, PNG had 19 upper-level health facilities and all these 19 facilities were surveyed (although

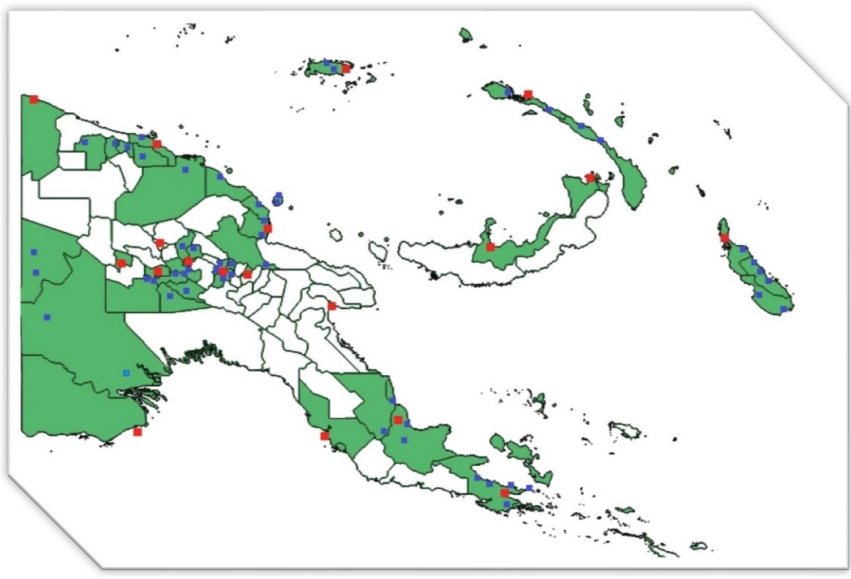

Figure 2 Map of Papua New Guinea with districts visited (green) and location of surveyed facilities.

one of the facilities was not fully operational). The upperlevel health facilities in the survey included the national referral hospital (Port Moresby General Hospital), 3 regional hospitals, and 15 provincial hospitals. At the national level, since about half of health centres and district/rural hospitals (levels 3 and 4) were Church-run, the survey design intended to sample equal number of publicly run and Church-run facilities. For selecting facilities at these two levels, between six (New Guinea Islands) and eight (Southern, Highlands and Momase) districts were randomly selected per region. The largest government-administered and Church-administered health facilities (one of each type based on outpatient numbers per annum as reported by the National Health Information System) were purposely selected per district. This sampling procedure allowed selection of 30 publicly run and 30 church-run facilities from the selected districts; however, during field visits, not all selected facilities were found to be operational. Where possible, closed health facilities were replaced by functional ones within the same district. In some districts there were no functional level 3 or 4 facilities, resulting in less than 60 facilities surveyed $(\mathrm{N}=54)$. Figure 2 shows the location of the health facilities surveyed for this study. The provinces shaded in green indicate where the survey was carried out. The red squares represent levels $5-7$ health facilities, while the blue squares represent levels 3 and 4 .

\section{Survey procedure}

The survey comprised a health facility assessment and costing instrument as well as interviews with healthcare providers, inpatients and outpatients. Each instrument is detailed in the survey report. ${ }^{21}$ The facility assessment questionnaire can be found in online supplemental file 1 of the article and standard health facility questionnaires were adapted to the PNG context using the NHSS document. ${ }^{20}$ Briefly, the health facility assessment collected information on various operational aspects of each health facility, while the costing instrument detailed expenditure on human resources, equipment and consumables used for the provision of healthcare services. Both these 
instruments were completed with health facility managers and administrators. Upper-level facilities offered many different types of specialised services and data collection at these levels required interviewing multiple facility personnel. The data collection was done by a team of five trained enumerators, who spent 3-5 days surveying each health facility. In total, 73 health facilities were surveyed.

\section{Informed consents for the survey}

For health facility costing and assessment, the survey team requested consent via email from the provincial, district and church health services, depending on the facility to be surveyed. In addition, consent was requested from the officer in charge of each of the health facilities. The travel plan to the facilities was finalised after the consents were granted. On the team's arrival in the facility, the supervisor of the team met the officer in charge to confirm the consent received earlier and to get verbal consent to initiate the interviews.

For interviews with healthcare workers and patients, informed consent was requested in writing. The interviews were conducted only after the consents were granted. As much as possible, visual and audible privacy was ensured for the interviews. All interview questionnaires were de-identified by assigning a code number. The code numbers are saved on a secure server at the PNGIMR.

\section{Public involvement}

Stakeholder consultations were involved in the design and early dissemination of this research. During the feasibility stage, priority of research questions, choice of outcome measures and methods were informed by discussions with stakeholders involving representatives from the National Department of Health, UN agencies, academics and other development partners in PNGs. The preliminary findings were also discussed with representatives from the National Department of Health, Provincial Health Authorities, hospitals and development partners in a stakeholder consultation workshop held in Port Moresby, PNG.

\section{Outcome measures}

The handbook on monitoring EmOC $^{18}$ identified a set of indicators to measure availability, access and provision of EmOC in a country or a region. Two types of measures were defined-the first type focuses on availability, adequate coverage and utilisation of services at national or subnational levels and the second type measures obstetric care related functions performed by health facilities. The functions identified to define the level of EmOC services offered from a health facility are: (1) administer parenteral antibiotics, (2) administer uterotonic drugs, (3) administer parenteral anticonvulsants, (4) manually remove the placenta, (5) remove retained products, (6) perform assisted vaginal delivery, (7) perform basic neonatal resuscitation, (8) perform surgery (eg, caesarean section) and (9) perform blood transfusion. When a facility can perform all the functions listed under $1-7$, it is considered a BEmOC provider while ability to perform all the nine functions defines the CEmOC provider. This study has used these nine measures to categorise health facilities as either a BEmOC or a CEmOC. Note that all these signal functions are defined by the ability to perform specific functions pregnant women need at the time of delivery. Ability to perform the functions does not necessarily imply that the facilities actually provided the services in the recent past.

Since this study is based on facility-level survey data, community or patient related health outcome measures are not directly observable. To compensate for this, we have used additional measures to understand readiness of health facilities in the provision of general inpatient care. Availability of basic medical equipment and supplies and physical condition of the facility (infrastructural variables) may affect willingness of clients to use services from the facilities. Another important intervention that may affect the demand for EmOC is the provision of family planning services. Family planning in PNG is expected to reduce TFR implying that need for maternity services should decline with family planning. Therefore, in addition to nine EmOC functions listed above, other outcome variables considered in this analysis are: (1) readiness of facilities to provide clinical services; (2) availability of family planning items and (3) availability of maternity care related equipment and materials. Availability of drugs and supplies is defined as having the item in stock at the time of the survey.

For the availability of equipment, instruments and supplies, several indexes were calculated to indicate degree of availability of the items. The index values range from 0 to 100,100 implying that all the items used for the construction of the index were available in all the facilities surveyed.

\section{Calculating readiness or availability index}

The analysis has used facility level data to derive the readiness indicators and ability to perform signal functions for each facility in the survey (Stata V.12 was used). The results are presented as descriptive tables (tables 1-4) to indicate the proportion of facilities having the instruments or able to perform the specific functions.

An equally weighted index was constructed based on the availability of the items included in each of the categories of service delivery. It reflects the per cent of all readiness aspects or variables satisfied by the health facilities in a specific category. For example, if a facility reports having an instrument, a value of 1.0 was assigned for the facility for that equipment. The availability index was constructed to show the per cent of listed equipment and items available in each of the facility categories. For example, if the family planning items availability index is 65 for level 3 and 4 facilities, it means that the facilities on the average had $65 \%$ of all the family planning equipment and items considered in the analysis. 
Table 1 Readiness index for provision of general clinical services by facility level in Papua New Guinea

\begin{tabular}{|c|c|c|c|c|c|c|c|c|}
\hline \multirow[b]{2}{*}{ Readiness indicators } & \multicolumn{4}{|c|}{ Level 3 and 4} & \multicolumn{2}{|c|}{ Level 5 and 6} & \multicolumn{2}{|c|}{ Level 7} \\
\hline & Public & $\%$ & Church & $\%$ & $\mathbf{N}$ & $\%$ & $\mathbf{N}$ & $\%$ \\
\hline Electricity connected to supply grid & 10 & 34 & 7 & 28 & 17 & 94 & 1 & 100 \\
\hline Electricity availability (supply or generator) & 20 & 69 & 21 & 84 & 18 & 100 & 1 & 100 \\
\hline Blackout last week & 8 & 28 & 6 & 24 & 15 & 83 & 0 & 0 \\
\hline Water from main line & 2 & 7 & 3 & 12 & 15 & 83 & 1 & 100 \\
\hline Water shortage last year & 18 & 62 & 11 & 44 & 7 & 39 & 0 & 0 \\
\hline Water available for use by healthcare providers & 24 & 83 & 21 & 84 & 18 & 100 & 1 & 100 \\
\hline Water available in delivery room & 13 & 45 & 18 & 72 & 18 & 100 & 1 & 100 \\
\hline Facility does direct blood transfusion & 3 & 10 & 3 & 12 & 16 & 89 & 1 & 100 \\
\hline $\begin{array}{l}\text { Facility has on-call room or space for healthcare providers to } \\
\text { take rest }\end{array}$ & 3 & 10 & 11 & 44 & 10 & 56 & 1 & 100 \\
\hline Facility has telephone or shortwave radio & 14 & 48 & 14 & 56 & 15 & 83 & 1 & 100 \\
\hline Facility has ambulance & 26 & 90 & 24 & 96 & 17 & 94 & 1 & 100 \\
\hline Ambulance out of service last year & 11 & 38 & 10 & 40 & 6 & 33 & 0 & 0 \\
\hline Facility has other vehicles & 8 & 28 & 5 & 20 & 18 & 100 & 1 & 100 \\
\hline Facility has operation theatre & 8 & 28 & 9 & 36 & 18 & 100 & 1 & 100 \\
\hline Index of readiness & 40.3 & & 48.5 & & 84.6 & & 100 & \\
\hline
\end{tabular}

Source: 2015 survey of health facilities in Papua New Guinea (survey conducted by this study).

\section{RESULTS}

\section{Facility readiness to provide clinical services}

Table 1 reports facility readiness in the provision of services. As shown, $95 \%$ (18 out of 19) of level 5-7 facilities were connected to the main electric supply grid but only about a third of level 3 and 4 facilities (17 out of 54). However, more than $80 \%$ of all facilities connected to the electric supply experienced blackout at least for some time in the week before the survey. All level 5-7 facilities had functional backup generators, while the percentage of level 3 and 4 facilities with backup generators was $76 \%$ for church-run facilities and $48 \%$ for public facilities. Half of the level 3 and 4 facilities with backup generators reported problems in operating the generator in the previous month.

If supply line and water tanks are considered, all level 5-7 facilities and $83 \%$ of level 3 and level 4 public health facilities and $84 \%$ of level 3 and level 4 church health facilities reported having access to water on the day of the survey. However, less than $10 \%$ of level 3 and 4 facilities were connected with water supply lines. Only $45 \%$ of level 3 and 4 public facilities had water connection to the delivery room (and water availability on the day of the survey) compared with $72 \%$ at church-run facilities.

A significant share of health facilities, $62 \%, 44 \%$ and $38 \%$ of level 3 and 4 public, level 3 and 4 church, and

Table 2 Availability of family planning items by facility level in Papua New Guinea

\begin{tabular}{|c|c|c|c|c|c|c|c|c|}
\hline \multirow[b]{2}{*}{$\begin{array}{l}\text { Family planning (FP) } \\
\text { items }\end{array}$} & \multicolumn{4}{|c|}{ Level 3 and 4 facilities } & \multicolumn{2}{|c|}{ Level 5 and 6 facilities } & \multicolumn{2}{|c|}{ Level 7 facilities } \\
\hline & Public (n) & Public (\%) & $\begin{array}{l}\text { Church } \\
\text { (n) }\end{array}$ & Church (\%) & Public (n) & $\begin{array}{l}\text { Level } 5 \text { and } \\
6(\%)\end{array}$ & Public (n) & $\begin{array}{l}\text { Level } 7 \\
(\%)\end{array}$ \\
\hline FP injections & 22 & 76 & 22 & 88 & 15 & 83 & 0 & 0 \\
\hline Condoms & 23 & 79 & 20 & 80 & 16 & 89 & 1 & 100 \\
\hline
\end{tabular}

Source: 2015 survey of health facilities in Papua New Guinea (survey conducted by this study). 
Table 3 Availability of supplies and equipment for maternity care in Papua New Guinea by health facility level

\begin{tabular}{|c|c|c|c|c|c|c|c|c|}
\hline \multirow{2}{*}{$\begin{array}{l}\text { Antenatal, pregnancy, obstetric and neonatal care } \\
\text { related equipment and supplies }\end{array}$} & \multicolumn{4}{|c|}{ Level 3 and 4 facilities } & \multicolumn{2}{|c|}{ Level 5 and 6 facilities } & \multicolumn{2}{|c|}{ Level 7 facility } \\
\hline & Public (n) & Public (\%) & Church (n) & Church (\%) & Public (n) & $\%$ & Public (n) & $\%$ \\
\hline Fetal stethoscope (or monitor) & 27 & 93 & 25 & 100 & 14 & 78 & 1 & 100 \\
\hline Tape measure & 23 & 79 & 22 & 88 & 16 & 89 & 1 & 100 \\
\hline Scale & 28 & 97 & 25 & 100 & 16 & 89 & 1 & 100 \\
\hline Ultrasound machine (and gel) & 28 & 97 & 25 & 100 & 17 & 94 & 1 & 100 \\
\hline Pelvic procedure instruments such as speculum & 18 & 62 & 22 & 88 & 16 & 89 & 1 & 100 \\
\hline Index: availability of antenatal care items & 76.85 & & 88.57 & & 87.30 & & 100 & \\
\hline Delivery light & 24 & 83 & 24 & 96 & 18 & 100 & 1 & 100 \\
\hline Partograph & 11 & 38 & 13 & 52 & 14 & 78 & 1 & 100 \\
\hline Steriliser & 15 & 52 & 16 & 64 & 13 & 72 & 1 & 100 \\
\hline $\begin{array}{l}\text { Facility has at least two skilled birth attendants } \\
\text { covering } 24 \text { hours a day }\end{array}$ & 21 & 72 & 19 & 76 & 18 & 100 & 1 & 100 \\
\hline Delivery kit (instruments, supplies) & 25 & 86 & 25 & 100 & 18 & 100 & 1 & 100 \\
\hline Resuscitation bag, newborn & 4 & 14 & 4 & 16 & 15 & 83 & 1 & 100 \\
\hline Eye drops or ointment for newborn & 27 & 93 & 25 & 100 & 18 & 100 & 1 & 100 \\
\hline Needles and syringes & 28 & 97 & 25 & 100 & 18 & 100 & 1 & 100 \\
\hline Sterile C-section instrument kits & 28 & 97 & 25 & 100 & 18 & 100 & 1 & 100 \\
\hline Cord supplies for newborn: clamps, ties, scissors & 2 & 7 & 5 & 20 & 12 & 67 & 1 & 100 \\
\hline IV sets, including sterilised needle and tube & 27 & 93 & 25 & 100 & 17 & 94 & 1 & 100 \\
\hline IV fluids, including normal saline and ringer lactate & 29 & 100 & 25 & 100 & 18 & 100 & 1 & 100 \\
\hline
\end{tabular}

Source: 2015 survey of health facilities in Papua New Guinea (survey conducted by this study).

level 5 and 6 facilities, respectively, experienced water shortages in 2014. The survey asked facility respondents whether the facility was responsible for maintaining the water supply system and it was observed that about $45 \%$ of public level 3-4 facilities were responsible for maintaining the water supply system. The proportions were $64 \%$ for church-run level 3 and 4 facilities and $68 \%$ for level 5-7 facilities.

Only $10 \%$ public $(n=3)$ and $12 \%$ church $(n=3)$ level 3 and 4 health facilities had ability to do direct blood transfusion. Proportion of facilities which could do blood transfusion was much higher, 89\% among level 5 and 6 facilities and $100 \%$ for level 7 . Percentage of health facilities that had operations theatre were much higher. $28 \%$ and $36 \%$ level of public and church level 3-4 health facilities and all level 5-7 health facilities had at least one operation theatre.

Both level 3 and 4 public-run and church-run health facilities show low readiness score for service delivery (table 1). Readiness indexes were 40.3 for level 3 and 4 public sector facilities, 48.6 for level 3 and 4 church-run facilities, 84.6 for level 5 and 6 facilities and 100 for the level 7 facility.
Availability of family planning items

Table 2 presents the availability of family planning products and supplies in surveyed health facilities. The availability index of family planning items was 81.6 for level 3 and 4 public sector health facilities, 84.0 for level 3 and 4 church-run facilities, and 88.9 for level 5 and 6 facilities. Non-availability of family planning injections in the level 7 facility reduced the overall index of family planning item availability for the facility to 66.7. Since there is only one facility at level 7 , non-availability of even a single item significantly reduces the overall index.

\section{Availability of supplies and equipment for maternity care}

A relatively large proportion of health facilities lacked very basic pregnancy and antenatal care related supplies and equipment as shown in table 3 . The index values for the availability of antenatal care items were 76.9 and 88.6 for level 3 and 4 public-run and Church-run facilities, respectively. The index was 87.3 for level 5 and 6 facilities and 100 for level 7 facility. The index of availability of obstetric and neonatal care items were worse in level 3 and level 4 facilities, 70.6 and 80.5, respectively for public and church facilities. The index was 95.52 for 
Table 4 Percentage of health facilities able to perform signal functions with categorisation of facilities into basic emergency obstetric care and comprehensive emergency obstetric care providers

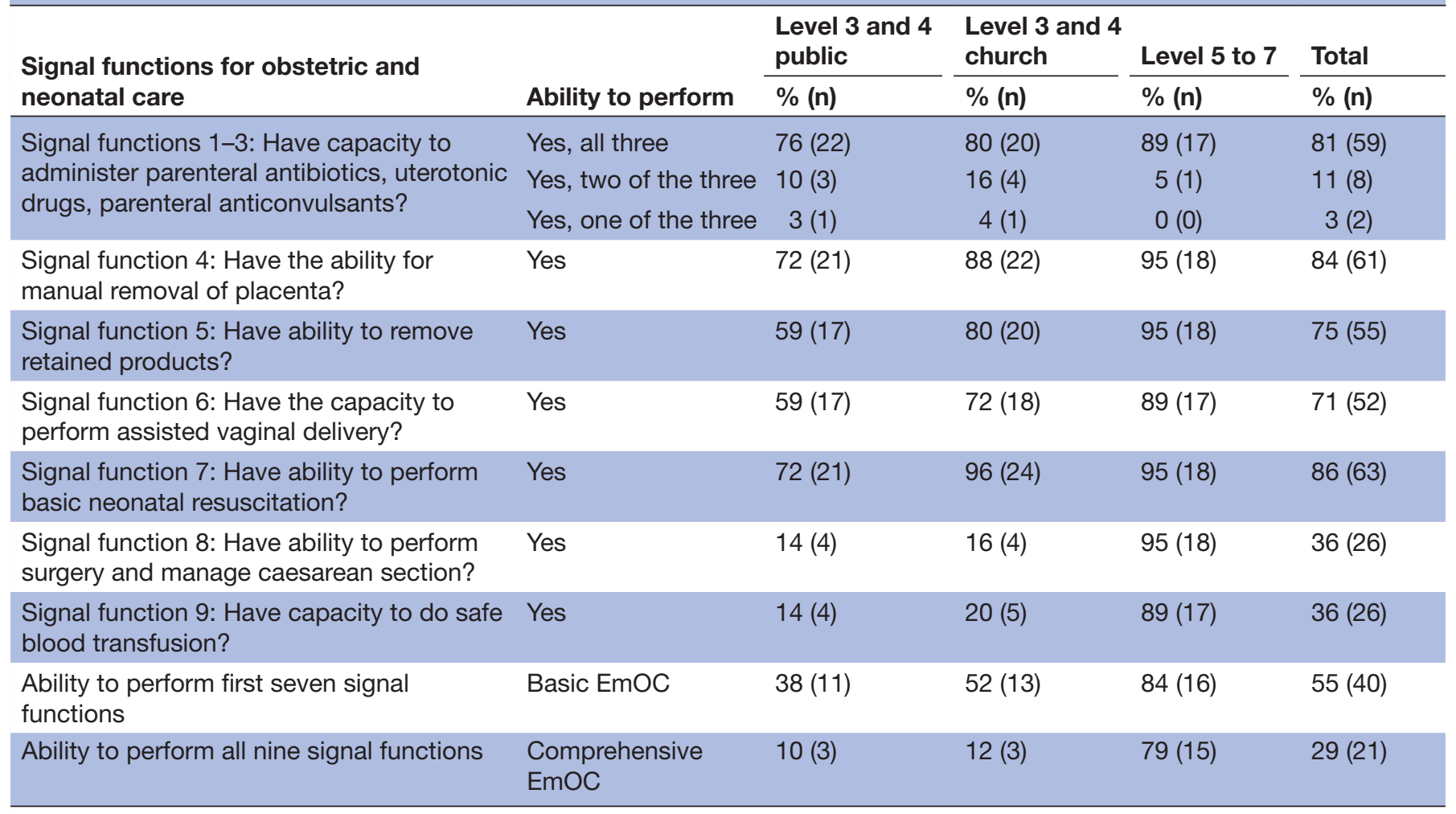

Source: 2015 survey of health facilities in Papua New Guinea (survey conducted by this study). EmOC, emergency obstetric care.

level 5 and 6 facilities. The survey also asked about the availability of vacuum extractors and forceps in the facilities for conducting deliveries. It is interesting that $74 \%$ of facilities reported having vacuum extractors and $95 \%$ reported having forceps although forceps are not used in PNG for deliveries.

\section{Ability to provide EmOC services}

Table 4 indicates the percent of facilities able to perform different obstetric functions. As mentioned earlier, WHO has defined nine functions to understand the level of obstetric services provided from the facilities. The survey questionnaire combined first three signal functions (capacity to administer parenteral antibiotics, uterotonic drugs, parenteral anticonvulsants) into one and asked the respondents to report if the facility was able to perform all the three functions, two of the three or one of the three functions. Most level 3-4 facilities, about $80 \% \quad(n=42)$, reported the ability to perform all these three functions. Two facilities at upper levels (levels 5-7) were not able to perform these three basic obstetric functions. One of the upper-level facilities in the sample was not fully functional at the time of the survey. Table 4 shows that $38 \%$ of church-run level 3-4 facilities and $52 \%$ of government-run level 3-4 facilities were BEmOC providers. Even among higher-level facilities (levels 5, 6 and 7), 11\% $(n=2)$ of facilities were not able to perform one or more of the necessary functions required to be considered a BEmOC provider.

If the signal functions for CEmOC are considered (all nine signal functions), only about $11 \%(n=6)$ of level 3 and 4 health facilities were found to be CEmOC units. About $15 \%$ of level 3 and 4 facilities had the capacity to manage a caesarean section or do blood transfusion. Not all level 5-7 facilities were CEmOC providers-21\% $(n=4)$ of upper-level facilities were not able to perform at least one of the nine signal functions.

\section{DISCUSSION}

The overall health facility infrastructural condition in PNG is quite poor. Most facilities reported the need for major building repairs and emphasised the lack of adequate toilets, stable electrical supply and consistent water supply. Many level 3 and 4 health facilities required better connectivity to electricity and clean water supply. One significant concern is the number of health facilities that did not have running water in the facility's delivery room. The quantity and quality of different types of clinical services provided crucially depends on the facility's readiness to offer services in general. Overall, level 3 and 4 facilities, both public and church-run, scored low on the readiness index, implying that these facilities were not very reliable providers of services and patient-confidence in 
these facilities are likely to be low. The survey also revealed the need for improving the supply of basic medical items at level 3 and 4 public health facilities. Level 3 and 4 public facilities show lower availability of different medical items compared with those in church-run facilities.

Comparison of health facility readiness across countries is often tricky because of differences in the level and comprehensiveness of facilities in different countries of the world. A World Bank report ${ }^{22}$ indicates that $98 \%$ of public hospitals in Indonesia had electricity; in Laos, the index of basic amenities was reported as $64 \%{ }^{23}$ compared with 58\% for PNG (weighted mean of the values in table 1).

This study showed that the index of availability of family planning supplies in levels 3 and 4 was about $83 \%$. Family planning supplies should be available in all facilities, especially at the lower levels, to ensure uninterrupted access at all times, which is clearly not the case for PNG. In addition, availability of family planning supplies does not necessarily mean utilisation of services. The findings from the most recent PNG DHS survey showed access to family planning services quite limited. One-quarter of currently married women have an unmet need for family planning, and only 59\% of currently married women are satisfied with family planning services. Among those who have received family planning, about 9 in 10 users obtained their modern family planning supplies from a public (government) source. Therefore, there is an urgent need to identify potential gaps in the provision and utilisation of family planning services to strengthen service provision from the government health facilities, especially at lower levels. Better access and utilisation of family planning services can help reduce maternal and child mortality. ${ }^{24-26}$

While $79 \%$ of level 5-7 facilities were found to be CEmOC providers, the fact that about a fifth were not able to provide CEmOC is a major concern, given that these are the higher-level referral hospitals in PNG. Consistent with the findings of this study, another study using a much smaller sample of facilities, concluded that the 'Capacity for essential surgery and anaesthesia services is severely limited in PNG due to shortfalls in physical infrastructure, human resources, and basic equipment and supplies'. ${ }^{16}$

The results from the survey can be used to derive national level estimates of obstetric care availability. Using the proportions of CEmOC facilities at different levels and the total number of facilities in PNG at these levels, the total number of facilities ready to provide comprehensive obstetric care was only 50 at the time of the survey in 2015. Even if we arbitrarily assume balanced geographic distribution of these facilities, an emergency obstetric case will have to travel $53 \mathrm{~km}$ each way, on average, to reach a CEmOC facility. The distance to the nearest CEmOC facility is so large that for many emergency cases this is virtually synonymous of not having access to CEmOC. To reduce maternal mortality and morbidity significantly, it is essential to lower the average distance to the nearest CEmOC facility ${ }^{27}$ implying that PNG will have to upgrade a significant number of levels 3,4 and 5 facilities. Geographic information systems and geographical modelling tools can help identify the optimal location of CEmOC facilities and existing facilities closest to the optimal locations can be upgraded in the short-run to improve access. ${ }^{28}$

All facilities at level 3 or above should be able to provide basic EmOC. To improve access to EmOC, most level 3 and 4 facilities should be considered for immediate upgrading to BEmOC provider or better. The survey of facilities indicated that about $45 \%$ of levels 3 and 4 facilities were not ready to provide BEmOC. Despite this low readiness, equipping about $15 \%-20 \%$ of these facilities to perform signal functions 5 and 6 can improve BEmOC availability from $55 \%$ of the facilities to about $80 \%$. Although maternal and child health is a priority area, PNG has not allocated enough resources to achieve improved access to maternity and neonatal services. PNG spends more than $4.3 \%$ of its GDP on health (about $\$ 109$ per capita in PPP dollars). Total health expenditure is not low compared with other countries with similar level of per capita income. ${ }^{29}$ However, a significant part of health resources, including human resources, particularly doctors, are concentrated in a few major hospitals. Therefore, the resource allocation at the lower-level health facilities (level 3 and level 4 facilities) are not sufficient. Reallocation of public sector resources to lower-level health facilities are needed to expand access to obstetric care and other preventive services.

To improve availability and access to quality maternity services in PNG, especially in remote rural areas, a programme of training and upskilling of Community Health Workers was adopted. ${ }^{30}$ Although the upskilling has increased utilisation of basic maternity services, significant reductions in maternal mortality will require access to hospital-based obstetric care. GoPNG may consider allocating funds to facilities, both public and church facilities, based on quantities of priority health services delivered rather than on number and mix of human resources and other administrative needs. ${ }^{31}$ While the effectiveness of such performance based financing depend on how the schemes are implemented, evidence in low-income and middle-income countries shows that the performance can be improved through financial incentives. ${ }^{32}$ From the demand side, past research has found that providing pregnant women with health vouchers to ensure financial protection for accessing medical care has increased utilisation of health services. ${ }^{33}$ The payments received through the vouchers will also encourage facilities to become more sensitive to the needs of pregnant women and would have incentives to invest to become fully functional EmOC providers. An initiative in two provinces in PNG that provided incentive packages to pregnant women increased facility-based supervised birth rates by $80 \%^{34}$ indicating that enhancing facility readiness combined with incentivising pregnant women to use health facilities will be very effective in improving maternal and neonatal health. 


\section{Study limitations}

Several limitations of the study should be mentioned here. First, it is not possible to indicate overall geographic access to primary healthcare services in PNG using the survey data because the study did not collect information from level 1 and 2 health facilities. However, these facilities do not provide obstetric care services although some basic services like family planning and antenatal care can potentially be organised at these levels. Second, the survey, strictly speaking, is not a representative survey of level 3 and 4 facilities. The survey design selected highdemand fully functional level 3 and 4 facilities in target districts and the definition of fully functional led to the choice of facilities that showed relatively high level of utilisation. Therefore, if anything, the results are likely to be significant overestimations of degree of readiness of the facilities in the provision of obstetric care and other related services in PNG. Even with this favourable selection of facilities, the percent of facilities able to perform BEmOC and CEmOC was quite low at levels 3 and 4 implying that the availability of obstetric care services could be significantly worse than what has been reported in this study. Third, the study did not try to connect the service availability and readiness with health outcomes of the population at the subnational level. In PNG, even the national level estimates of mortality and morbidity are considered unreliable and subnational level estimates would suffer from even higher degree of error in estimation. In any case, facility level information clearly indicates that many of the functional facilities are not ready to provide obstetric health services and a significant proportion of facilities lack medical equipment, instruments and supplies for the provision of quality maternity and neonatal services.

\section{CONCLUSIONS}

Inability of a health facility, irrespective of whether it is a primary, secondary and tertiary care facility, to provide obstetric care and other related services is an important concern for any healthcare system. It is especially true for a country like PNG where maternal and infant mortalities are high alongside a high fertility rate. Improved availability and utilisation of family planning services can help reduce the demand for EmOC, lower maternal and neonatal mortality/morbidity and improve access to maternity services. Lowering the need for maternity services through interventions like family planning, however, is unlikely to improve access to maternity care significantly in the short-run. Supply-side interventions are necessary to ensure that the services are available in strategically located health facilities. Improving facility infrastructure, equipping the facilities with essential medical equipment and supplies and ensuring the presence of trained personnel in health facilities are needed to make the facilities BEmOC or CEmOC providers. Since the number of facilities in PNG offering EmOC is quite low compared with the needs, all level 3 and 4 facilities should be upgraded to at least the BEmOC level. Surveybased estimates suggest that only 50 facilities in PNG can be considered CEmOC providers and this number is inadequate to ensure equitable access to emergency obstetric cases. Increasing the number of CEmOC providers is urgently needed.

Contributors $\mathrm{XH}$ : conceptualisation, methodology, supervision, project administration, resources, writing-original draft, writing—review and editing. MMK: conceptualisation, methodology, supervision, formal analysis, writing-original draft, writing — review and editing. JP: conceptualisation, methodology, data curation, data validation, writing-review and editing. OPMS: data curation, data validation, writing-review and editing. MMK is acting as guarantor of the paper.

Funding This work was funded by the World Bank's Trust Fund supported by Australia's Department of Foreign Affairs and Trade. World Bank contract number: 7171956, Principal Investigator: M Mahmud Khan. Date: 1 July 2014.

Map disclaimer The inclusion of any map (including the depiction of any boundaries therein), or of any geographic or locational reference, does not imply the expression of any opinion whatsoever on the part of BMJ concerning the legal status of any country, territory, jurisdiction or area or of its authorities. Any such expression remains solely that of the relevant source and is not endorsed by BMJ. Maps are provided without any warranty of any kind, either express or implied.

Competing interests None declared.

Patient consent for publication Not applicable.

Ethics approval This study does not involve human participants. The study was approved by the PNG Institute of Medical Research (IMR) Institutional Review Board (IRB) and the PNG Medical Research Advisory Committee (MRAC). The following approval numbers were allocated to the study: IRB No. 1414, 7 August 2014; MRAC No. 14.26, 10 November 2014.

Provenance and peer review Not commissioned; externally peer reviewed.

Data availability statement Data are available upon reasonable request. No additional data are available. Researchers interested in 2015 PNG Facility Assessment Survey data can contact Dr. Xiaohui Hou at xhou@worldbank.org and copy the PI of the project, Dr M Mahmud Khan, at the email address Mahmud. Khan@uga.edu with a statement on the reasons for requesting the dataset and types of analyses to be conducted.

Supplemental material This content has been supplied by the author(s). It has not been vetted by BMJ Publishing Group Limited (BMJ) and may not have been peer-reviewed. Any opinions or recommendations discussed are solely those of the author(s) and are not endorsed by BMJ. BMJ disclaims all liability and responsibility arising from any reliance placed on the content. Where the content includes any translated material, BMJ does not warrant the accuracy and reliability of the translations (including but not limited to local regulations, clinical guidelines, terminology, drug names and drug dosages), and is not responsible for any error and/or omissions arising from translation and adaptation or otherwise.

Open access This is an open access article distributed in accordance with the Creative Commons Attribution Non Commercial (CC BY-NC 4.0) license, which permits others to distribute, remix, adapt, build upon this work non-commercially, and license their derivative works on different terms, provided the original work is properly cited, appropriate credit is given, any changes made indicated, and the use is non-commercial. See: http://creativecommons.org/licenses/by-nc/4.0/.

ORCID iDs

Xiaohui Hou http://orcid.org/0000-0002-8219-996X

M Mahmud Khan http://orcid.org/0000-0003-0301-5657

\section{REFERENCES}

1 Islam MT, Hossain MM, Islam MA, et al. Improvement of coverage and utilization of EmOC services in southwestern Bangladesh. Int J Gynaecol Obstet 2005;91:298-305.

2 Turab A, Ariff S, Habib MA, et al. Improved accessibility of emergency obstetrics and newborn care (EmONC) services for maternal and newborn health: a community based project. BMC Pregnancy Childbirth 2013;13:136.

3 Chavula K, Likomwa D, Valsangkar B, et al. Readiness of hospitals to provide kangaroo mother care (KMC) and documentation of KMC 
service delivery: analysis of Malawi 2014 emergency obstetric and newborn care (EmONC) survey data. J Glob Health 2017;7:020802.

4 Ameh CA, Mdegela M, White S, et al. The effectiveness of training in emergency obstetric care: a systematic literature review. Health Policy Plan 2019;34:257-70.

5 Lee ACC, Cousens S, Darmstadt GL, et al. Care during labor and birth for the prevention of intrapartum-related neonatal deaths: a systematic review and Delphi estimation of mortality effect. BMC Public Health 2011;11 Suppl 3:S10.

6 Paxton A, Bailey P, Lobis S, et al. Global patterns in availability of emergency obstetric care. Int J Gynaecol Obstet 2006;93:300-7.

7 Banke-Thomas A, Wright K, Sonoiki O, et al. Assessing emergency obstetric care provision in low- and middle-income countries: a systematic review of the application of global guidelines. Glob Health Action 2016;9:31880.

8 Government of Papua New Guinea. National health plan 2011-2020, volume 1: policies and strategies, 2010.

9 Mola G, Kirby B. Discrepancies between national maternal mortality data and international estimates: the experience of Papua New Guinea. Reprod Health Matters 2013;21:191-202.

10 Robbers G, Vogel JP, Mola G, et al. Maternal and newborn health indicators in Papua New Guinea - 2008-2018. Sex Reprod Health Matters 2019;27:52-68.

11 PNG National Department of Health. Health information systems, 2019.

12 WHO, UNICEF, UNFPA, World Bank Group, and the United Nations Population Division. Trends in maternal mortality: 2000 to 2017. Geneva: World Health Organization, 2019.

13 National Statistical Office (NSO) [Papua New Guinea] and ICF. Papua New Guinea demographic and health survey 2016-18. Port Moresby, Papua New Guinea, and Rockville, Maryland, USA: NSO and ICF, 2019.

14 Mola G, Aitken I. Maternal mortality in Papua New Guinea 19761983. P N G Med J 1984;27:65-71.

15 Dennis AT. Reducing maternal mortality in Papua New Guinea: Contextualizing access to safe surgery and anesthesia. Anesth Analg 2018;126:252-9.

16 Martin J, Tau G, Cherian MN, et al. Survey of the capacity for essential surgery and anaesthesia services in Papua New Guinea BMJ Open 2015;5:e009841.

17 Donabedian A. Evaluating the quality of medical care. Milbank Mem Fund Q 1966;44:166-203.

18 WHO, UNFPA, UNCEF, \& AMDD. Monitoring emergency obstetric care: a Handbook. Geneva: World Health Organization, 2009.

$19 \mathrm{NDOH}$. Christian health services technical assistance mission report. Papua New Guinea: National Department of Health: Port Moresby, 2013.
20 Government of PNG (GoPNG). National health service standards for Papua New Guinea 2011-2020. Volumes 1 and 2, 2011.

21 Khan MM, Hou X, Saweri OPM. Service delivery by health facilities in Papua New Guinea: report based on a countrywide health facility survey. Washington DC: The World Bank Group, 2017.

22 World Bank. Universal Maternal Health Coverage? Assessing the Readiness of Public Health Facilities to Provide Maternal Health Care in Indonesia. Washington, DC: World Bank, 2014.

23 World Bank. Maternal health out-of-pocket expenditure and service readiness in Lao PDR. Washington, DC: World Bank, 2013.

24 Chola L, McGee S, Tugendhaft A, et al. Scaling up family planning to reduce maternal and child mortality: the potential costs and benefits of modern contraceptive use in South Africa. PLoS One 2015;10:e0130077.

25 Utomo B, Sucahya PK, Romadlona NA, et al. The impact of family planning on maternal mortality in Indonesia: what future contribution can be expected? Popul Health Metr 2021;19:2.

26 Winikoff B, Sullivan M. Assessing the role of family planning in reducing maternal mortality. Stud Fam Plann 1987;18:128-43.

27 McKinnon B, Harper S, Kaufman JS, et al. Distance to emergency obstetric services and early neonatal mortality in Ethiopia. Trop Med Int Health 2014;19:780-90.

28 Ebener S, Stenberg K, Brun M, et al. Proposing standardised geographical indicators of physical access to emergency obstetric and newborn care in low-income and middle-income countries. BMJ Glob Health 2019;4:e000778.

29 World Bank. Health financing system assessment. Papua New Guinea: World Bank, Washington, 2017.

30 Mola G. Upskilling experienced female CHWs currently working in maternity care in rural health facilities in maternity care skills 2020.

31 Cairns A, Hou X. Financing the frontline : an analytical review of provincial administrations' rural health expenditure 20062012. Health, Nutrition, and Population (HNP) discussion paper. Washington, D.C: World Bank Group, 2015. https://hubs. worldbank.org/docs/ImageBank/Pages/DocProfile.aspx?nodeid= 25991656

32 Paul E, Renmans D. Performance-Based financing in the Heath sector in low- and middle-income countries: is there anything whereof it may be said, see, this is new? Int J Health Plann Manage 2018;33:51-66

33 Brody CM, Bellows N, Campbell M, et al. The impact of vouchers on the use and quality of health care in developing countries: a systematic review. Glob Public Health 2013;8:363-88.

34 Mola G. A pioneering approach to birthing, PNG attitude, 2019. Available: https://www.pngattitude.com/2019/12/a-pioneeringapproach-to-birthing.html 